\title{
Fault Ride Through Capability Enhancement of Permanent Magnet Synchronous Generator-based Wind Energy Conversion System
}

\author{
Walid S. E. Abdellatif ${ }^{1,2}$, Noura A. Nour Aldin ${ }^{1}$, Ahmed M. Azmy ${ }^{3}$, Ahmed A. Salem ${ }^{4}$ \\ ${ }^{1}$ Electrical Department, Faculty of Technology and Education, Suez University, Suez, Egypt. \\ ${ }^{2}$ Department of Electronics and Electrical Communications Engineering, Higher Institute of Engineering and \\ Technology - Kafr Elsheikh, Egypt. \\ ${ }^{3}$ Department of Electrical Power and Machines Engineering, Faculty of Engineering, Tanta University, Tanta, Egypt. \\ ${ }^{4}$ Electrical Engineering Department, Faculty of Engineering, Suez Canal University 41522 Ismailia, Egypt.
}

\begin{abstract}
With the speedy increase of wind energy in electric networks, many important issues could emerge, where the most important matter is to maintain the connection of wind generators during fault conditions. With different faults in the electrical network, the voltage at the point of common coupling (PCC) decreases causing unwanted transients in the stator currents. This results in substantially increased fluctuations in the DC-link voltage (Vdc). To avoid this negative impact, it is a must to maintain the capability of wind generators to continue linked to the network during faults, which is depicted as low voltage ride through (LVRT) capability. This paper investigates the LVRT enhancement by two techniques, the first is based on Braking Chopper $(B C)$ and the second method is based on electrical double-layer capacitors (EDLC), or Supercapacitor Energy Storage System (SCESS), under abnormal conditions. The full model of the permanent magnet synchronous generator (PMSG) system and FRT technique are performed in MATLAB/Simulink platform. As a consequence of the findings, both the BC and SCESS are capable to provide satisfactory performance with superior FRT capability for the SCESS compared to the BC.
\end{abstract}

Keywords: Wind energy, Permanent magnet synchronize generator (PMSG), supercapacitor (SCESS), braking chopper (BC), and fault ride-through (FRT).

\section{INTRODUCTION}

The prosperity in wind energy conversion systems (WECS) has resulted in a significant increase in the utilize of wind energy in the power network. This development increase in wind turbine was not a foreseen happening and, subsequently grid codes for network integration of renewable energy are changing to preserve the clean energy in unison with the network [1]. Through fault and voltage sag states, wind farms are not allowed to be disconnected but they must operate, with traditional power plants, to support the main grid system during these conditions [2]. Currently, variable-speed wind energy (VSWE) is more advantageous than constant-speed wind energy as a result their better wind power production and reliability [3-5]. Previously, doubly-fed induction generators (DFIGs) were the more commonly used technology for VSWE in the industry. DFIGs can submit reactive and active power by a back-to-back converter (BTB) [6-8]. Nevertheless, this tendency has been variated recently with the evolution of VSWE with lower cost $/ \mathrm{kW}$, 
higher power availability, and greater power density/reliability. Presently, PMSG has been found to be promising because of its features of higher power density, higher efficiency, and lower maintenance costs $[9,10]$. PMSG can be disconnected from the grid by a BTB converter. Through the network faults, the internal voltage drop results in a high reduction in the output active power that is delivered from the DC-link to the network by the gridside converter (GSC). Rather, the DC-link capacitor stores the generated active power, which raises the DC-link voltage and represents a real hazard for the capacitor. The majority of the presented solutions utilize exterior devices to enhance the LVRT capability of the PMSG. The exterior devices comprise BC [12-14], flexible AC transmission system (FACTS) [15-17] and energy storage devices [18-20]. In [21], a novel control construction is demonstrated corresponding to regulating the $\mathrm{DC}$ voltage $(\mathrm{Vdc})$ by the machine-side converter (MSC). On the other hand, the grid-side converter accomplishes full power point monitoring. When faults happen in the network, the created power from the PMSG is decreased, which led to the DC-input link's power to diminish. Consequently, the voltage of the DC-link remains fixed [21].

In [22], the DC voltage (Vdc) is compared with a threshold voltage. The output of a D-type flip-flop acts as a pulse generator when the DC-link voltage reaches the threshold value. Therefore, a BC will be turned on by clock frequency. Supercapacitors and batteries are the usually used energy storage devices, because of their energy densities and high power, respectively [23-26]. In [27], the performance of a supercapacitor merged with the PMSG system is investigated. A booster connects the supercapacitor to the DC link. To minimize the inverter's harmonics, a booster inductor is utilized between the network and the inverter. The generator's input wind power is compared to the reference output power of the wind energy. If the output power exceeds the reference value, it is stocked in the supercapacitor, while the stocked energy in the capacitor will be released when the output power is lower than the reference to recompense the reduction of the input power. In [28], an effective control strategy for integrating SCESS with PMSG-based WTGs is suggested in order to ride during the failure and soft the fluctuations of the generated power. During a network fault, the proposed controller is used to stock the produced power from the WTG in the SCESS. To monitor the DC link voltage, the energy storage is built into the DC link using a bidirectional buck-boost converter. In [29], using of static synchronous compensator with the PMSG system is demonstrated for operation without interruption through network disorders. The implementation of the direct-drive wind energy system is improved with SCESS and STACOM. In [30] discussed the use of mechanical system inertia to decrease SCESS power capacity. The d-axis reference current assumed to be zero. In normal state, SCESS enhances power smoothing and during network faults, SCESS is enabled to soak up the power deviation between the network and generator. In contrast, the speed reference in the MSC is adjusting higher than that in the usual state to stock some energy in the system inertia and, thus, the generator output power will be decreased. As a result, SCESS's rating could be decreased. In [31], SCESS reference current is acquired by the voltage of DC-link error after crossing during PI controller. Moreover, to decrease the energy storage price, the rating of SCESS is adapted as $30 \%$ of the BTB converter rating.

This paper presents SCESS and BC techniques for enhancing FRT capability of PMSG system. The prime contributions in this article are summarized in the following points:

- Improving the FRT capability of PMSG system under various fault states contain symmetrical and asymmetrical types. 
- Comparing the BC and SCESS methods for FRT enhancement of PM synchronous generator-based wind turbines.

- $\quad$ Evaluating the performance of PM synchronous generator system supported by the $\mathrm{BC}$ and $\mathrm{SC}$ with increased short circuit periods.

This article is regulated as follows: Section 2 demonstrates the modeling of WECS with devices utilized for FRT enhancement and LVRT enhancement technique. Section 3 demonstrates the simulation results. Finally, the article is summarized in Portion 4.

\section{Modeling of Wind Energy Conversion System (WECS) according to FRT Strategies}

As delineated in Figure 1, the configuration of PM synchronous generator-based wind turbine with the control system comprises mechanical and electrical parts. The SCESS and BC are putted in parallel with the DC-link capacitor in the DC link. The models of the PM synchronous generator with SCESS and BC, including the dynamics of the system and control strategy, are executed in MATLAB/Simulink platform, with a rated wind speed of $14 \mathrm{~m} / \mathrm{s}$. The control of the PM synchronous generator system at most depends on BTB converters divided into MSC and GSC, respectively [32]. The first converter, recognized as the MSC, is communicated to the stator windings of the PM synchronous generator, whilst the other is referred to as GSC, which is communicated to the network at the PCC by an AC filter. As a result, a full separation between the generator and the network is achieved by a DC-link. Every converter's power scheme consists of a three-leg voltage source converter. The MSC controller is primarily used to optimize the output power of wind energy by controlling the shaft speed. The grid-side inverter controls both active and reactive power flow. It controls the inverter to keep the DC-link voltage steady, which regulates the flow of active power automatically.

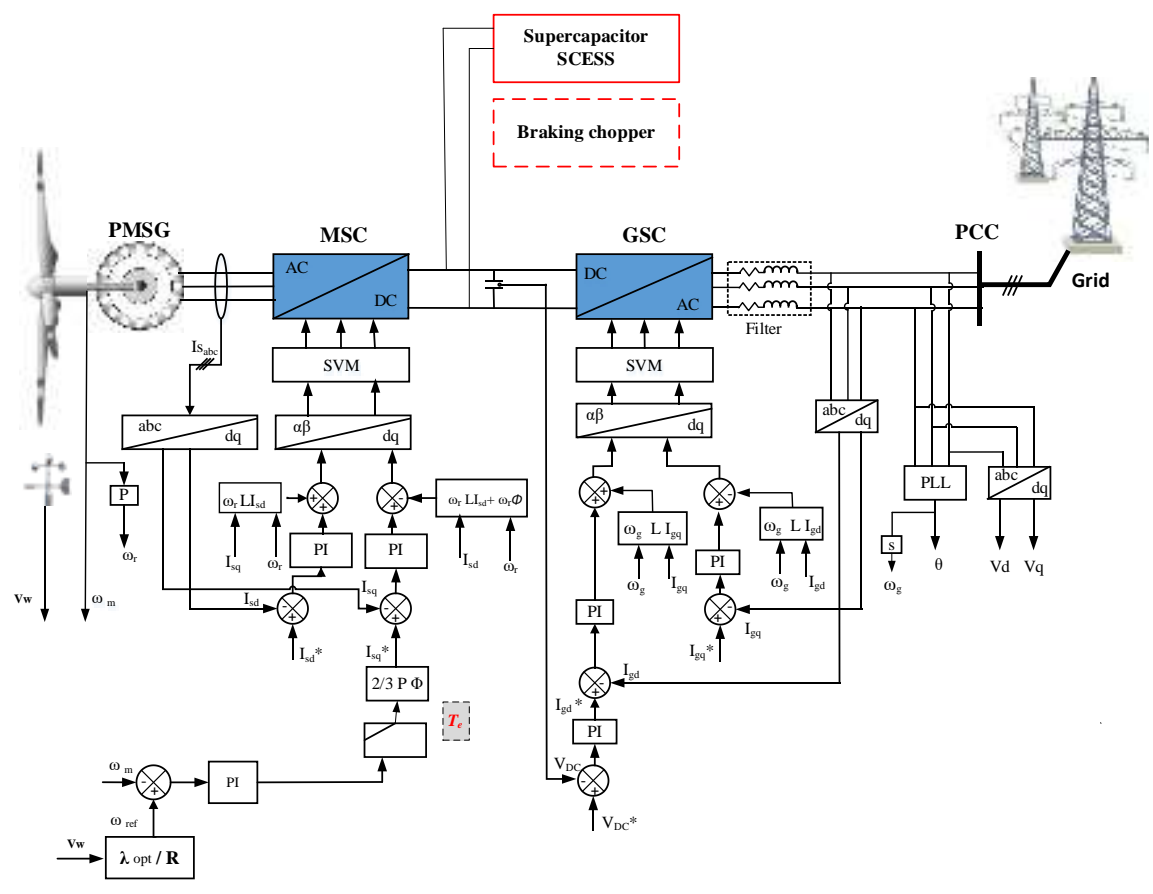

Figure 1. The configuration of wind energy based upon PMSG along with the controlling system under a fault at PCC. 
The aerodynamic power from the wind is usually described as follows: [32]

$$
P_{m}=\frac{1}{2} \rho A v^{a} C_{P}\left(\lambda_{*} \beta\right)
$$

where: $\rho$ is the density of air $(\mathrm{kg} / \mathrm{m} 3), \mathrm{V}$ is the wind speed $(\mathrm{m} / \mathrm{s}), \mathrm{A}$ is swept area, $\mathrm{Cp}$ is the power coefficient, $\lambda$ the tip speed ratio and $\beta$ is the pitch angle of the blade.

The tip-speed ratio is defined as:

$$
\lambda=\frac{\omega_{m} r}{v}
$$

where: $\omega_{m}$ is the turbine speed

The mechanical torque, $\mathrm{T}_{\mathrm{m}}$, is given as follows:

$$
T_{m}=\frac{P_{m}}{\omega_{m}}
$$

As presented in Figure 2, it the $C_{p}$ and $\lambda$ relationships are displayed at different pitch degrees. The turbine must work at the maximum value of $c_{p}$, ensuring maximum power value, where the maximum value of $C_{p}$ should match the optimal tip speed ratio (2_opt) [32]. According to wind turbine parameters, the maximum power occurs at the point, $\beta=0^{\circ}$, and $C_{p_{-} \max }=0.48$ as gained from Fig. 2

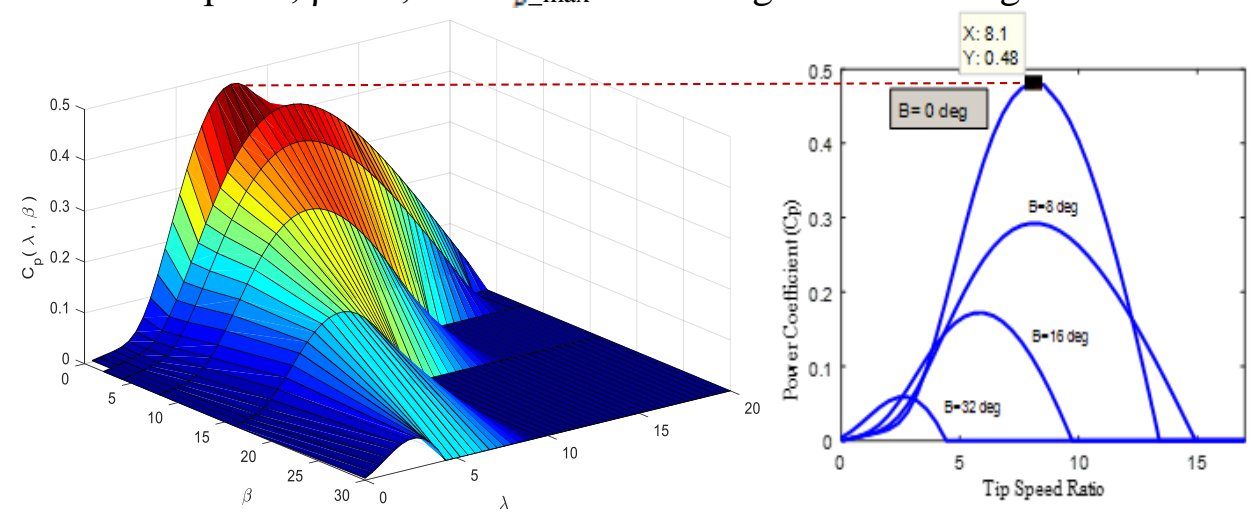

Figure 2.Wind Turbine Characteristics [32].

\section{A. PMSG Modeling}

The PMSG dynamic model has been demonstrated in [33-35]. The stator voltages SD and Vs. related to dq reference frame can be clarified:

$$
\begin{aligned}
& V_{s d}=-R_{S} I_{s d}-\mathrm{L}_{s} \frac{d I_{s d}}{d t}+\mathrm{L}_{s} \mathrm{I}_{s q} \omega_{\mathrm{r}} \\
& V_{s q}=-R_{s} I_{s q}-\mathrm{L}_{s} \frac{d I_{s q}}{d t}+\mathrm{L}_{s} \mathrm{I}_{s d} \omega_{\mathrm{r}}+\omega_{\mathrm{r}} \phi
\end{aligned}
$$

where Rs and Ls are the resistance and inductance of the stator, respectively, the electrical angular speed is abbreviated as $\omega \mathrm{r}$ and $\phi$ is the permanent magnetic flux.

Figure 3 demonstrates the d-q-axis equivalent diagrams of PM synchrounce generator. 


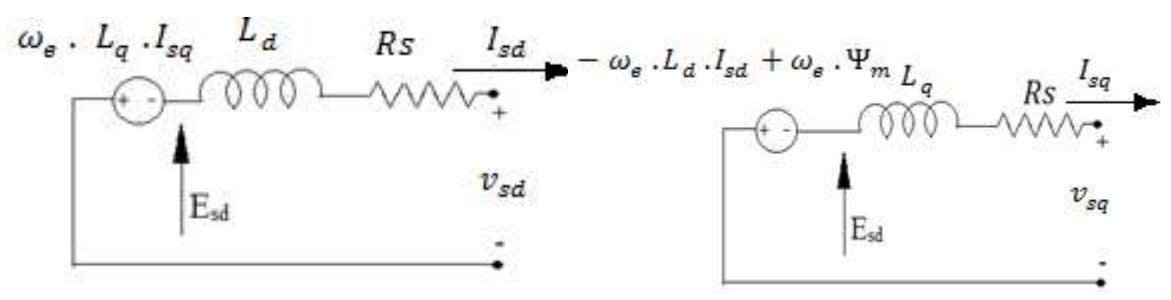

Figure 3. Equivalent model of PMSG.

The electromagnetic torque, $T_{\varepsilon}$, is described as follows [35], [36]:

$$
T_{\varepsilon}=\frac{a}{2} \mathrm{P} I_{s q}\left(\left(L_{d}-L_{q}\right) I_{g d}+\phi\right)
$$

where $L_{d}$ and $L_{q}$ are the dq axis inductance with $L_{d q}=L_{q}=L_{g}$ in surface mounted PMSG and $\mathrm{P}$ is the number of pole pairs. The electromagnetic torque given by equation (6) can be rewritten as:

$$
\mathrm{Te}=\frac{a}{2} P I_{a q} \phi
$$

\section{B. Braking Chopper}

A braking chopper (BC), also known as a crowbar, is connected to the DC-link to store the excess active power during a network fault. [39]. BC comprises a high-power resistor and a series switch that is opened to a resistor bypass in usual working. The switch is closed when a network fault is detected and the resistor is linked in parallel with the DClink. Thus, the DC-link voltage is repressed because the active power overflow is dissipated by the resistor as shown in Figure 3 (a). The features of $\mathrm{BC}$ are the cheap price and simple control. The duty ratio for the BC switch is planned using the DC-link voltage error after going through a PI controller, as demonstrated in Figure 4 (b). The BC existence cannot improve the level of reactive power to the network because it is required to dissipate all active generated power in order to enable reactive power injection to the gird.

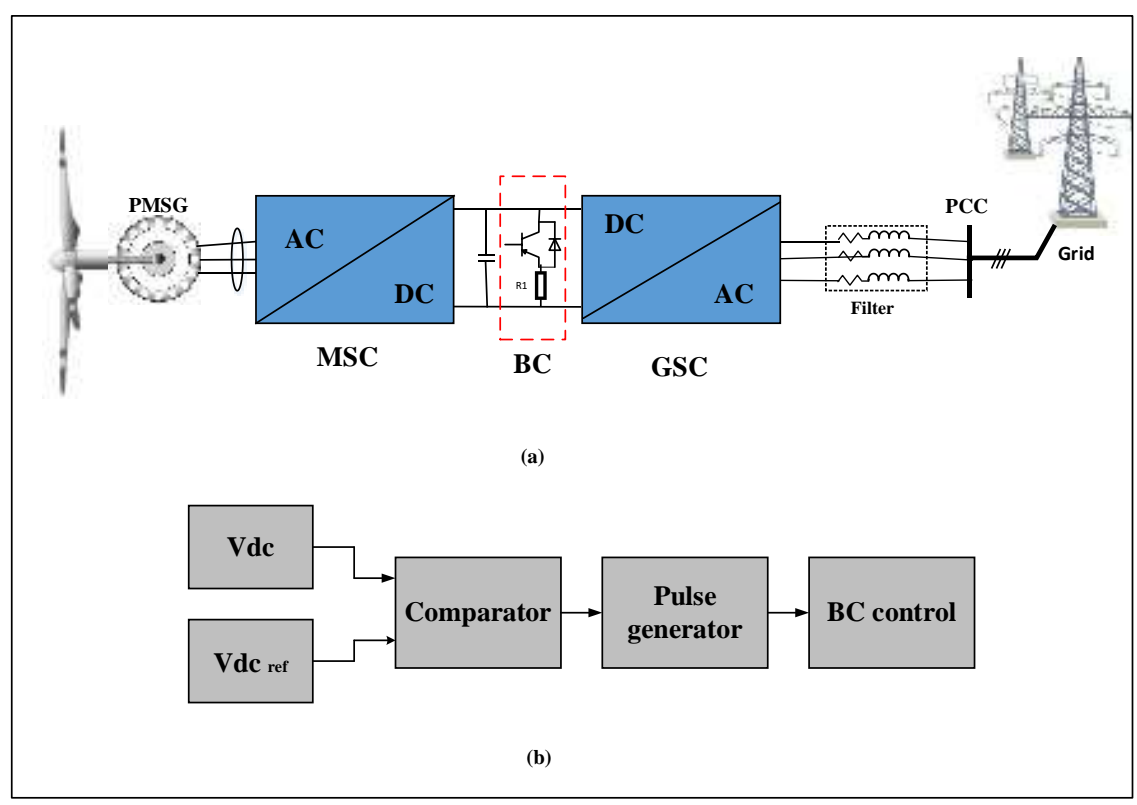

Figure 4.PMSG-based wind turbine with BC method (a) Construction and (b) block diagram of $\mathrm{BC}$ controller 


\section{Supercapacitor energy storage system (SCESS)}

It is one of the energy storage systems that has interesting features such as the short time constant. Hence, it's a good fit for apps that need quick answers in a limited amount of time. It has a long-lifetime and it is an attractive method for improving LVRT. During fault, it is effective for absorbing the variation in power between the network and the generator. The SCESS is inserted at the DC link via a DC/DC converter allowing the capability of bidirectional control of the power flow as demonstrated in Figure 5. The bidirectional converter has two operating modes. When turning on the first switch, as a buck converter, it charges the SCESS, and when turning on the second switch, as a converter, it empties the supercapacitors. to transmit energy to the DC link capacitor. The DC link's voltage controls these operating manners. To avoid the SCESS from overcharging and under-discharging, a lower limit of 50\% of the maximal SCESS voltage is set. The state of charge (SoC) control keeps the SCESS voltage between 0.5 VSC max and VSC max, where VSC max is the maximal SCESS voltage. The system must operate between these two voltages in order to use $75 \%$ contained in the SCESS. The LSC buckboost inductor is designed with a duty cycle of 0.5 in the boost operating mode as presented in (8)[41].

$$
V d c=\frac{V s c}{1-d}
$$

where $\mathrm{d}$ is a duty cycle and Vsc is voltage of SCESS

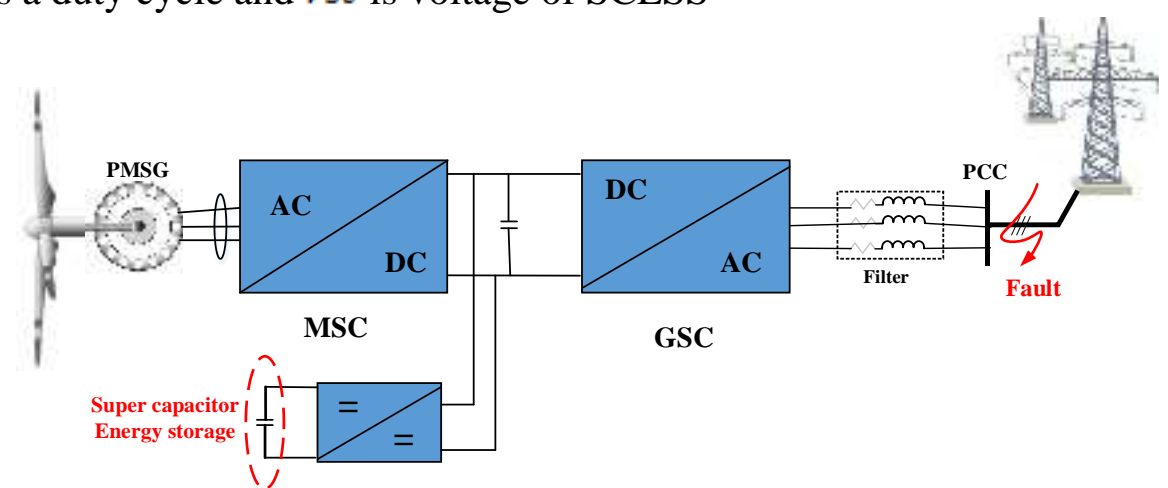

Figure 5. Block diagram of PMSC system with SCESS energy storage.

To produce the firing signals for S1 and S2, a comparison of the actual inductor current $I_{S C}$ with the reference SCESS current $l_{\text {Scref }}$ as shown in Figure 6.

The reference current $I_{\text {scref }}$ and control signal Cs are given in Laplace domain as:

$$
\begin{aligned}
& I_{S C r e f=}\left(V_{d c_{y} r f}-V_{d e}\right) *\left(K_{P O}+\frac{K_{I D}}{s}\right) \\
& C_{s}=\left(I_{S C \text { ref }}-I_{S C}\right) *\left(K_{P I}+\frac{K_{I I}}{s}\right)
\end{aligned}
$$

where $K_{p}{ }^{s} s$ and $K_{I} s_{s}$ are the proportional and integral constants of the PI controller.

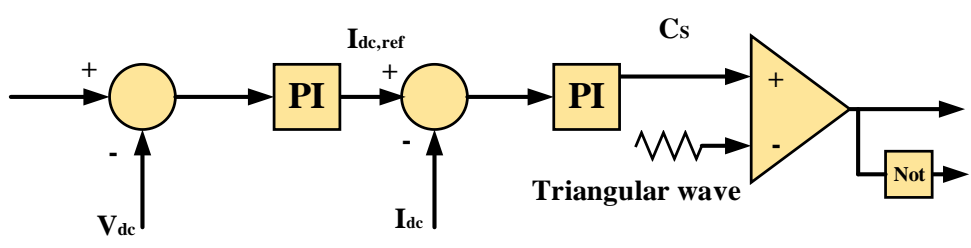

Figure 6. Converter control of SCESS. 


\section{Simulation Results}

The system under study is PMSG-based wind energy linked to the network. Through symmetrical and asymmetrical grid faults, time-series simulation results are acquired. Then, the SCESS method is compared with the BC method. The FRT capability of the wind energy is analyzed and evaluated for the following conditions: symmetrical fault, asymmetrical fault (single line to ground fault and double line to ground fault), increasing short circuit period, and changing the braking chopper resistance.

\section{A. Symmetrical Fault}

The simulation results of PMSG without and with the braking chopper and supercapacitor energy storage during a symmetrical 3- $\Phi$ fault, with a simulation time of 23 s. In Figure 7(a), 3- $\Phi$ fault is applied between 18.3 and $18.45 \mathrm{~s}$. When the grid fault occurred, the voltage at PCC is reduces almost to zero. Figure 7 (b) illustrates a comparison between the response of the RMS current at PCC behavior with using SCESS, $\mathrm{BC}$ and without using these schemes. The current reaches about $2.4 \mathrm{pu}$, which is approximately two-and-a-half times the peak current under normal conditions. After inserting BC and SC schemes, the current is considerably limited, where the current signal is reduced from 2.4 pu to $1.5 \mathrm{pu}$ and $1.35 \mathrm{pu}$ for the BC scheme and the SCESS scheme, respectively. Thus, SCESS shows more limitations to current at fault.

Figure 7 (c) illustrates the voltage of the DC-link during network symmetrical faults. The rated voltage of DC-link capacitance is $470 \mathrm{~V}$ and the value of the capacitor is 2 $\mathrm{mF}$. Trough the fault period, the DC-link voltage is increased to $2200 \mathrm{~V}$ (4.5 pu) without inserting the schemes, which is a high value because PMSG's active power isn't able to be passed into the network during the fault period and it will continue to charge the DC-link capacitor to a high degree. After removing the fault, the voltage of DC can progressively return back to its nominal level trough releasing the excess active power to the network. Nevertheless, the DC voltage is inappropriate because it damages power transfer equipment permanently. with linking the $\mathrm{BC}$ to the $\mathrm{DC}$ link in parallel, the voltage of DC link is decreased from 2200 (4.5 pu) to $500 \mathrm{~V}$ (1.11 pu) only.

The $\mathrm{BC}$ is turned on and the excess active power is dissipated in the $\mathrm{BC}$ resistance. So, depending on the new grid code demands, the WECS must inject reactive power to the network during the faults/voltage dips. It is not possible to achieve this requirement using the BC solution. In contrast, SCESS shows that the voltage of DC link is decreased from $2200(4.5 \mathrm{pu})$ to $485 \mathrm{~V}(1.03 \mathrm{pu})$. Figure 7 (d) demonstrates the active power at PCC during the fault, where the active power drops to approximately zero without connecting any scheme, but after the fault, the active power increases to $2.2 \mathrm{pu}$. With connecting the $\mathrm{BC}$, the active power snap back to the nominal value after the fault period without increase, which occurs also with SCESS. Consequently, the electromagnetic torque of PM synchronous generator is decreased to nearly zero without schemes as shown in Figure 7 (e). After BC and SCESS insertion, the electromagnetic torque is limited.

Figure 7 (f) depicts the q-axis current of PMSG, which demonstrates the active component of current. The reduction of this current helps to minimize the DC-link voltage, which occurs with connecting the BC and SCESS. Figure $7(\mathrm{~g})$ presents the d-axis current of the network, which shows the active component of current. This current increases to 2.2 $\mathrm{pu}$ without any scheme, while the d-axis current of grid reduces to $1.30 \mathrm{pu}$ with $\mathrm{BC}$ connection. It is obvious that SCESS shows more limitations to the d-axis current of the grid to nearly 1.22. In Figure $7(\mathrm{~h})$, the rotor speed increases without triggering the devices, but more limitations occur when connecting BC and SCESS. 
Table 1: Symmetrical Fault Behavior

\begin{tabular}{|c|c|c|c|}
\hline $\begin{array}{c}\text { Values in pu } \\
\text { PCC }\end{array}$ & Without LVRT & With BC & With SCESS \\
\hline $\begin{array}{c}\text { RMS currents at } \\
\text { DC-link voltage }\end{array}$ & 2.4 & 1.5 & 1.35 \\
\hline $\begin{array}{c}\text { d-axis current of } \\
\text { the grid }\end{array}$ & 2.2 & 1.11 & 1.03 \\
\hline
\end{tabular}

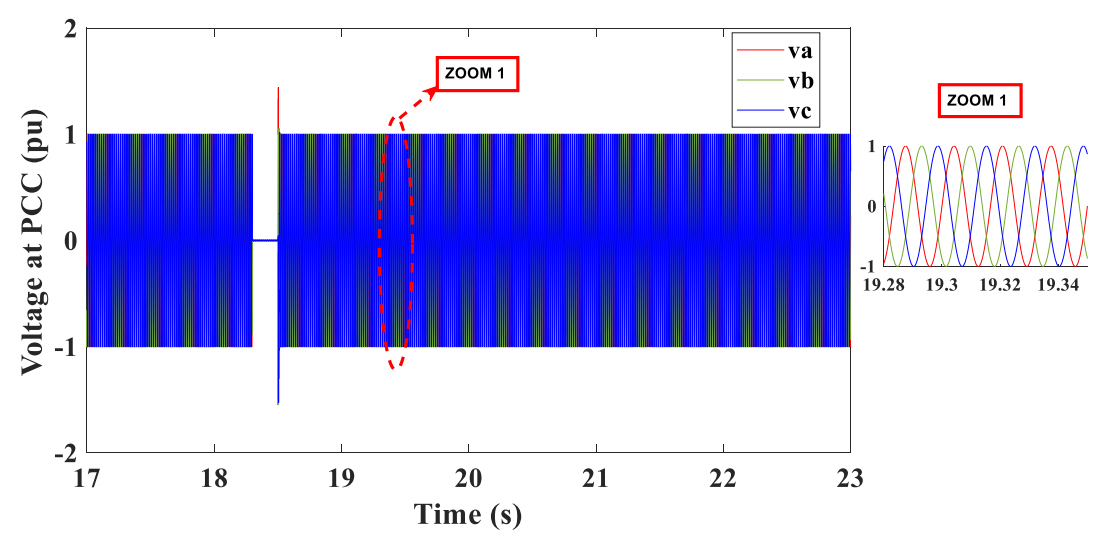

(a)

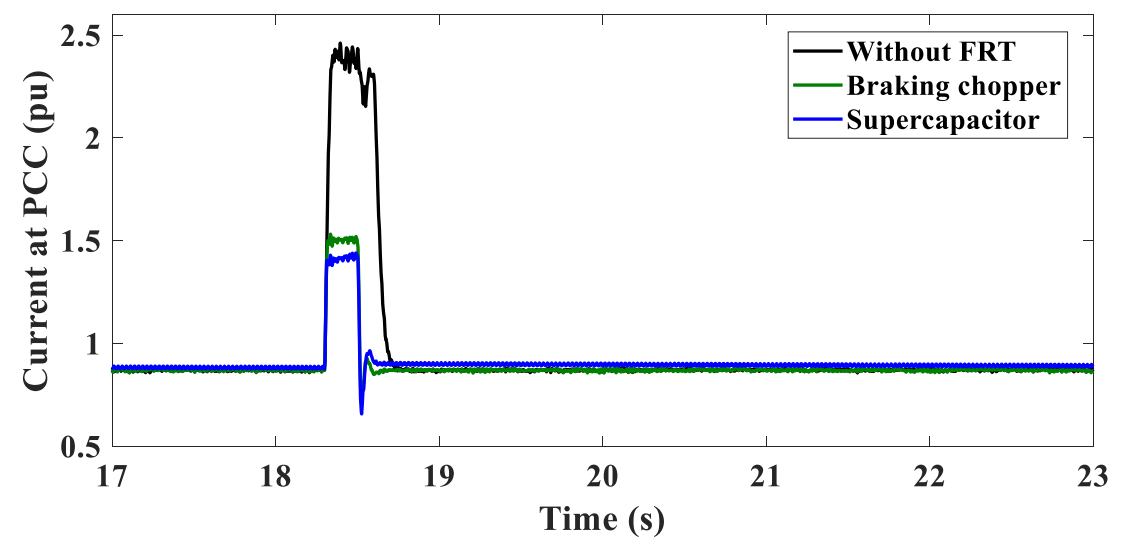

(b)

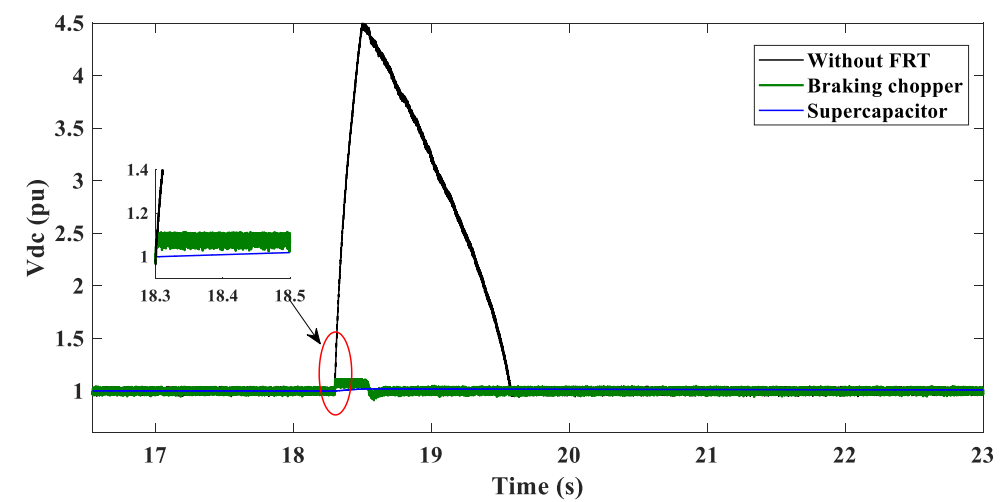

(c) 


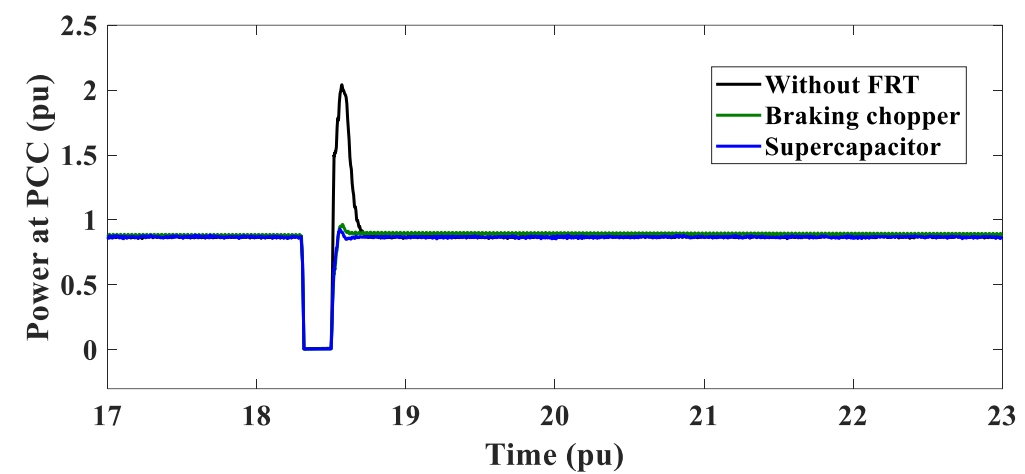

(d)

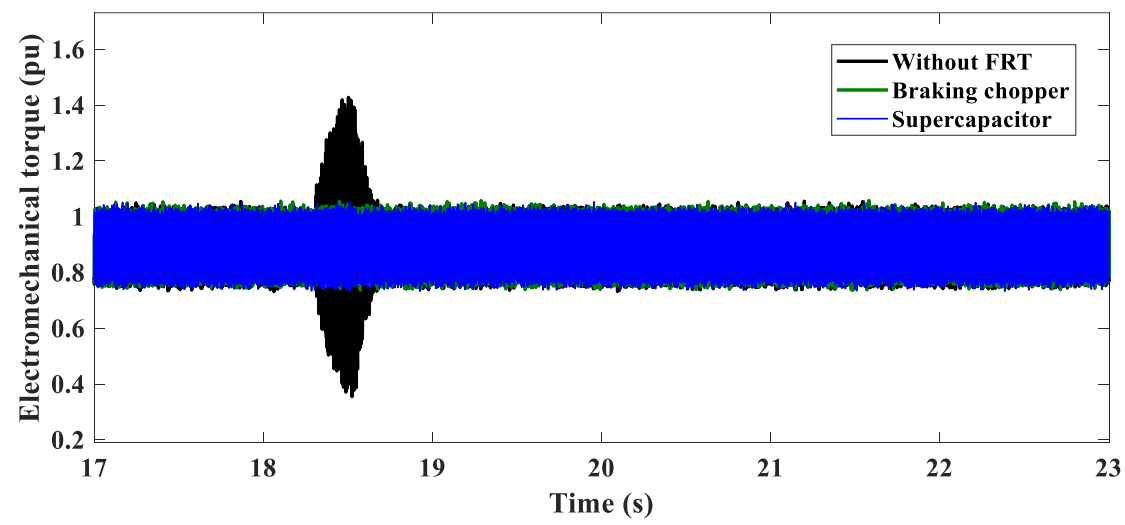

(e)

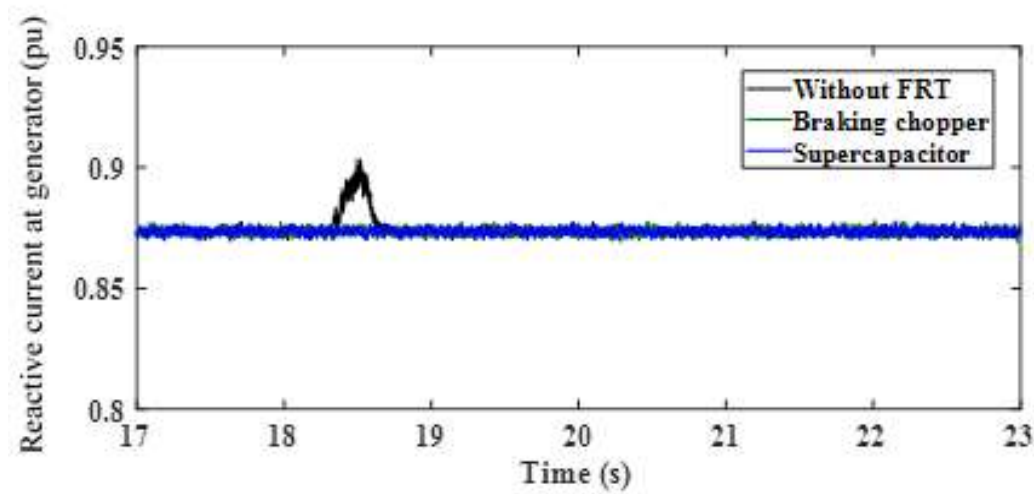

(f)

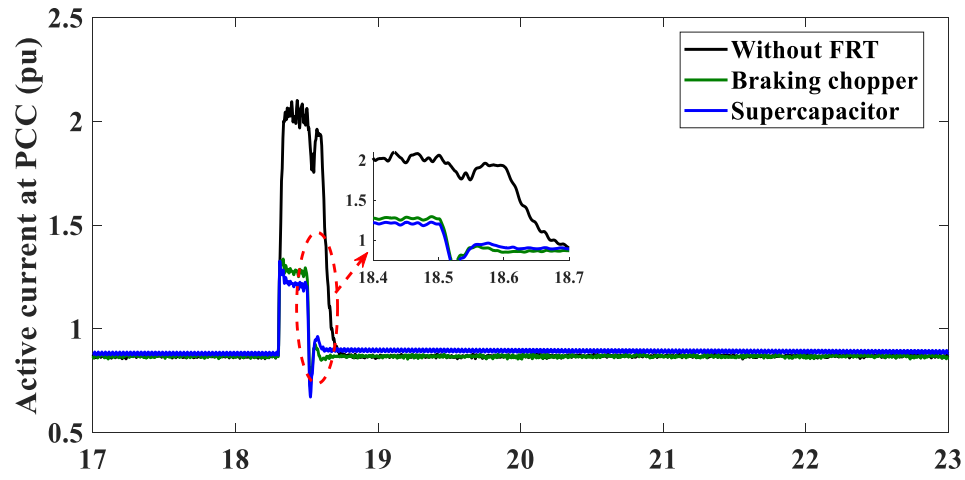

(g) 


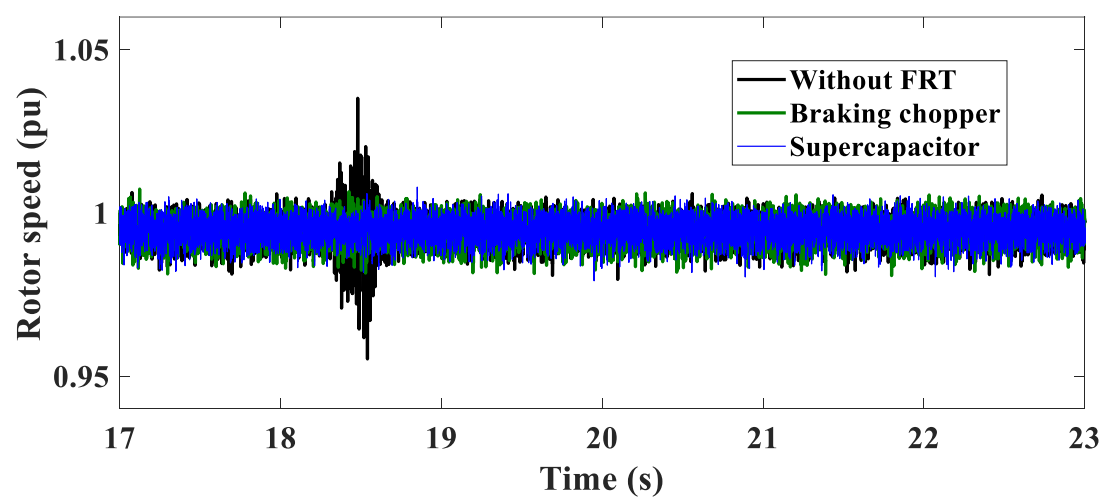

(h)

Figure 7. Dynamic response of PMSG under 3- $\Phi$ symmetrical fault with BC and SC schemes: a) voltage at PCC; b) current at PCC; c) DC link voltage; d) active power; e) electromagnetic torque; f) reactive current at generator; g) active current at PCC; h) rotor speed.

\section{B. Asymmetrical Fault}

\section{Single Line-to-Ground Fault (L-G)}

Asymmetrical faults are less severe compared to symmetrical faults, but asymmetrical three-phase short circuit (S.C) are most common than symmetrical S.C. The voltage of phase "a" is decreased a proximity zero as a result of a S.C of the single line to ground on phase "a" through the fault, as demonstrated in Figure 8 (a). The RMS currents of the grid for a S.C of the single line to ground is demonstrated in Figure 8 (b). For this fault, the RMS currents at PCC raise but with various magnitudes, where the value of current at PCC is 1.31 pu before connecting the BC and SCESS. This value reduces to 1.08 pu after addendum the BC method, while the connection of the SCESS scheme limits the RMS current at PCC to $1 \mathrm{pu}$.

The influence of the SCESS on the voltage of DC-link compared to the BC is present in Figure 8 (c). During network faults, the SCESS provides faster response and lowers voltage deviation. The DC-link voltage value without any scheme is $1.3 \mathrm{pu}$, but it is reduced when connected the $\mathrm{BC}$ scheme to a value of $1.1 \mathrm{pu}$. When linking the SCESS scheme, the voltage of DC-link value is decreased to 1.005 pu. In Figure 8 (d), the electromagnetic torque without any scheme method has higher oscillations than with BC and SCESS schemes. Figure 8 (e) depicts the q-axis current of PMSG, which demonstrates the active component of current. The reduction of this current helps to limited the DC-link voltage, and this occurs with connecting the BC and SCESS. Figure 8 (f) presents the daxis current of the network, which shows the active component of current. This current increases to $1.2 \mathrm{pu}$ without schemes, while the d-axis current of grid reduces to $1.03 \mathrm{pu}$ with BC connection. In addition, SCESS shows more limitations to the d-axis current of the grid that reduces to $0.98 \mathrm{pu}$. consequently, as shown from the compared results, the protection scheme provides whole control of the PM synchronous generator to prevent damaging effects during the asymmetrical $1-\Phi$ grid fault. 
Table 2: Single Line-to-Ground Fault Behavior

\begin{tabular}{|c|c|c|c|}
\hline $\begin{array}{c}\text { Values in pu } \\
\text { PCC }\end{array}$ & Without LVRT & With BC & With SCESS \\
\hline RMS Current at & 1.31 & 1.08 & 1 \\
\hline $\begin{array}{c}\text { DC-link voltage } \\
\text { grid }\end{array}$ & 1.3 & 1.1 & 0.98 \\
\hline \begin{tabular}{c} 
d-axis current of the \\
\hline
\end{tabular}
\end{tabular}

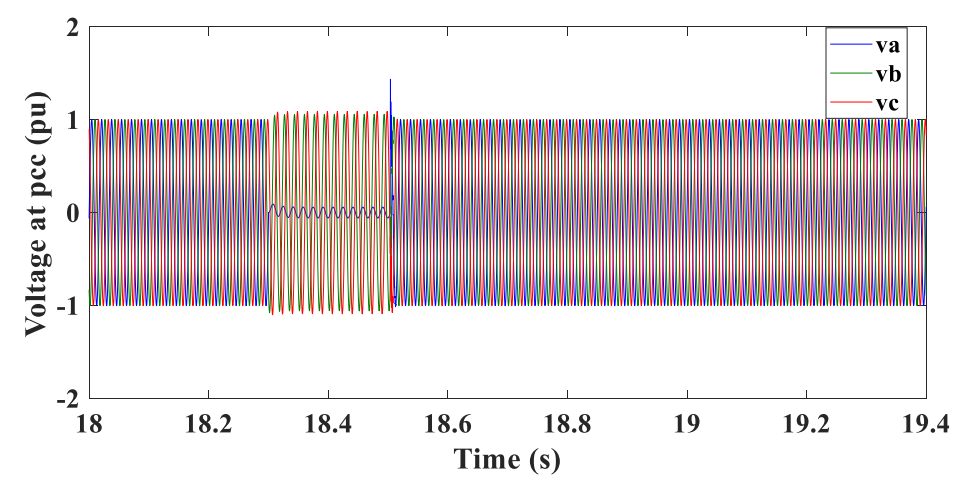

(a)

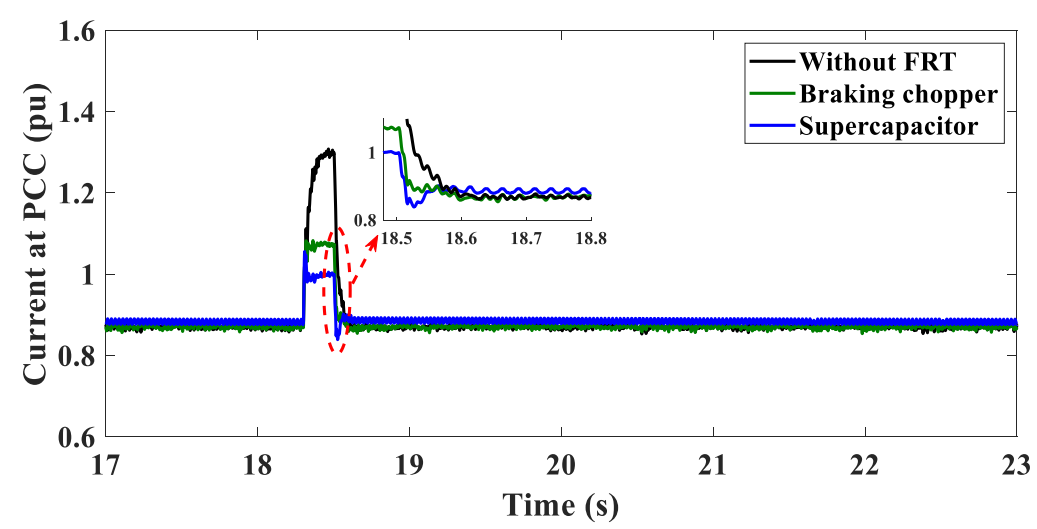

(b) 


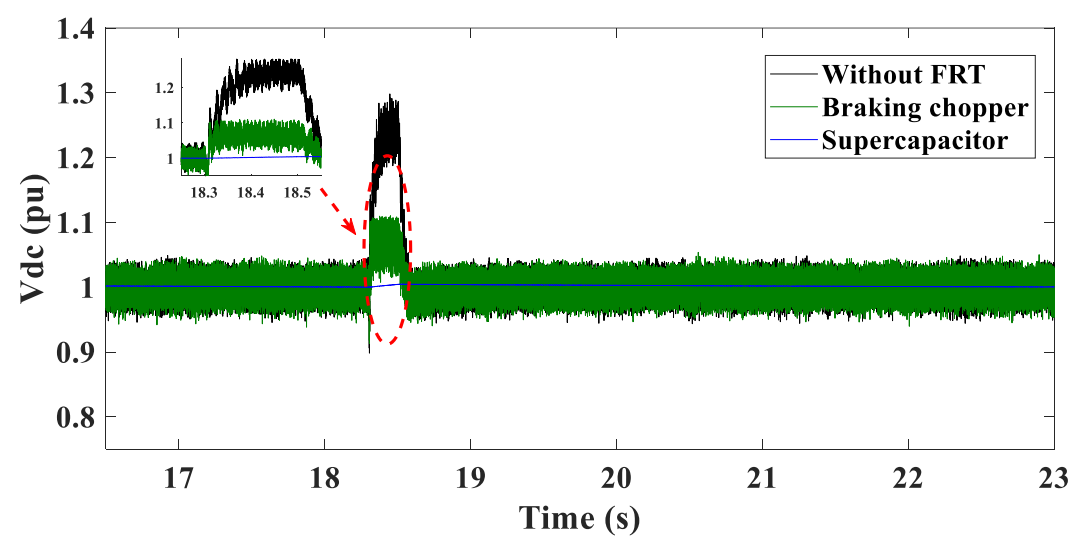

(c)

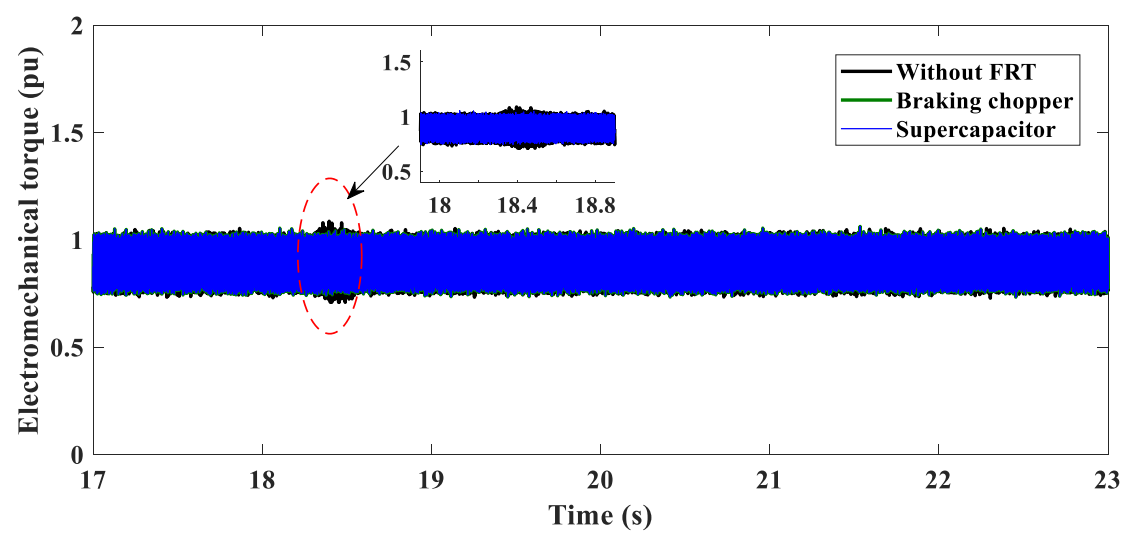

(d)

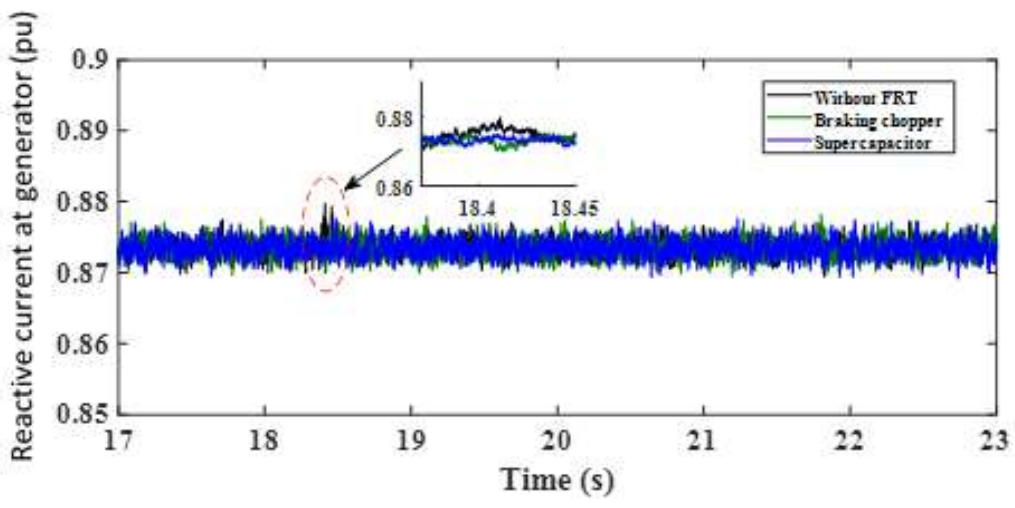

(e) 


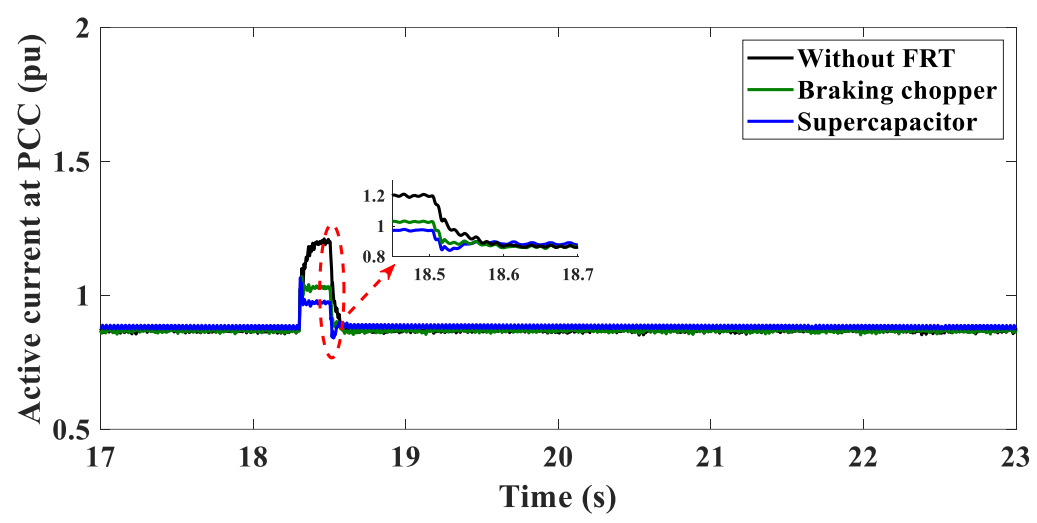

(f)

Figure 8. Dynamic response of PMSG under 1- $\Phi$ to ground asymmetrical fault with BC and SC schemes: a) voltage at PCC; b) current at PCC; c) voltage of the DC link; d) electromechanical torque; e) rotor speed; f) reactive current.

\section{Double-Line-to Ground Fault (LLG)}

L.G fault are marginally more serious than LLG fault. For a LLG fault, the same scenario as for a L.G fault is used. The fault between phases "a" and "b" is simulated with a duration of $150 \mathrm{~ms}$ as demonstrated in Figure 9 (a). The RMS currents at PCC that has high values during the fault reaching 2.3 pu as presented in Figure 9 (b). After connecting $\mathrm{BC}$, the fault current is reduced from $2.3 \mathrm{pu}$ to $1.28 \mathrm{pu}$, after applying the SCESS, the fault current is limited to 1.19 pu. The DC-link voltage is shown in Figure 9 (c), where it is restored faster around its nominal value $(470 \mathrm{~V})$ after connecting the SCESS. The DC-link voltage value without any scheme is $2.05 \mathrm{pu}$, but when connected to the $\mathrm{BC}$ method the value is minimized to $1.1 \mathrm{pu}$. When connecting the SCESS method, the voltage of the DClink value is minimized to $1.001 \mathrm{pu}$. In Figure 9 (d), the electromagnetic torque without schemes has higher oscillations than with BC and SCESS. In Figure 9 (e), the rotor speed increases without triggering the devices, but more limitations occur when connecting BC and SCESS systems. Figure 9 (f) depicts q-axis current of PMSG. The reduction of this current helps to limit the DC-link voltage, and this occurs with connecting the BC and EDLC. Figure. 9 (g) presents d-axis current of the network, which shows the active component of current. This current increases to 1.95 pu without connecting devices, while the d-axis current of grid reduces to $1.15 \mathrm{pu}$ with $\mathrm{BC}$ connection SCESS shows more limitations to the $\mathrm{d}$-axis current of the grid to nearly $1.09 \mathrm{pu}$. consequently, as shown from the compared results, the protection scheme provides whole control of the PM synchronous generator to prevent damaging effect during the asymmetrical LLG fault. 
Table 3: Double-Line-to Ground Fault Behavior

\begin{tabular}{|c|c|c|c|}
\hline Values in pu & Without LVRT & With BC & With SCESS \\
\hline $\begin{array}{c}\text { RMS Current at } \\
\text { PCC }\end{array}$ & 2.3 & 1.28 & 1.19 \\
\hline DC-link voltage & 2.05 & 1.1 & 1.001 \\
\hline $\begin{array}{c}\text { d-axis current of the } \\
\text { grid }\end{array}$ & 1.95 & 1.15 & 1.09 \\
\hline
\end{tabular}

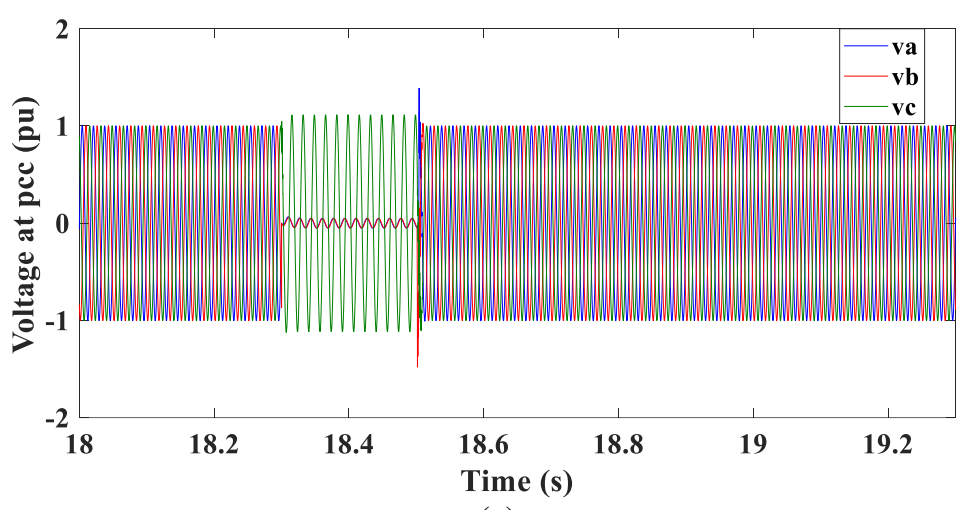

(a)

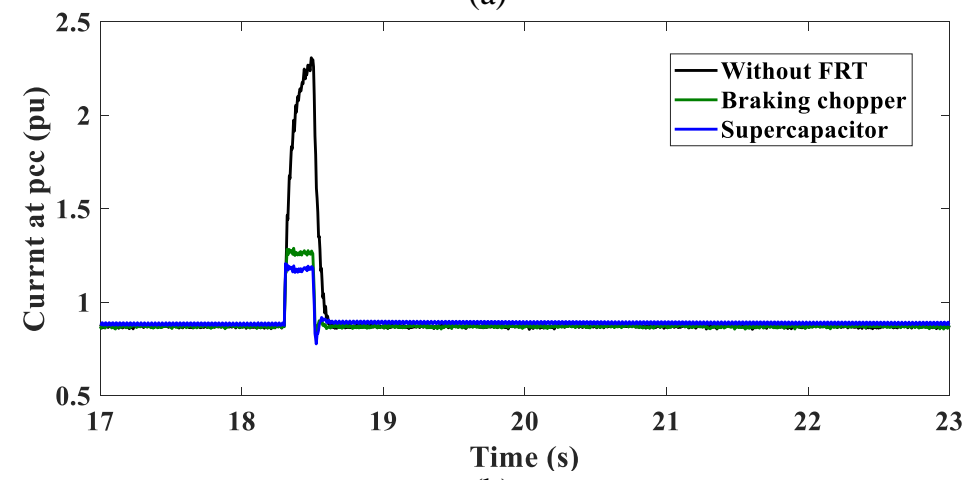

(b)

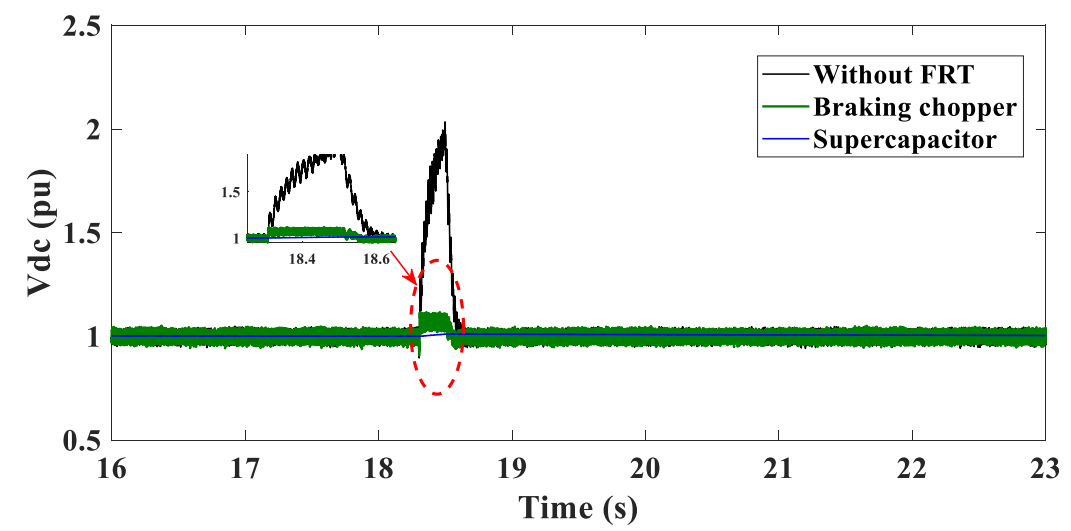

(c) 


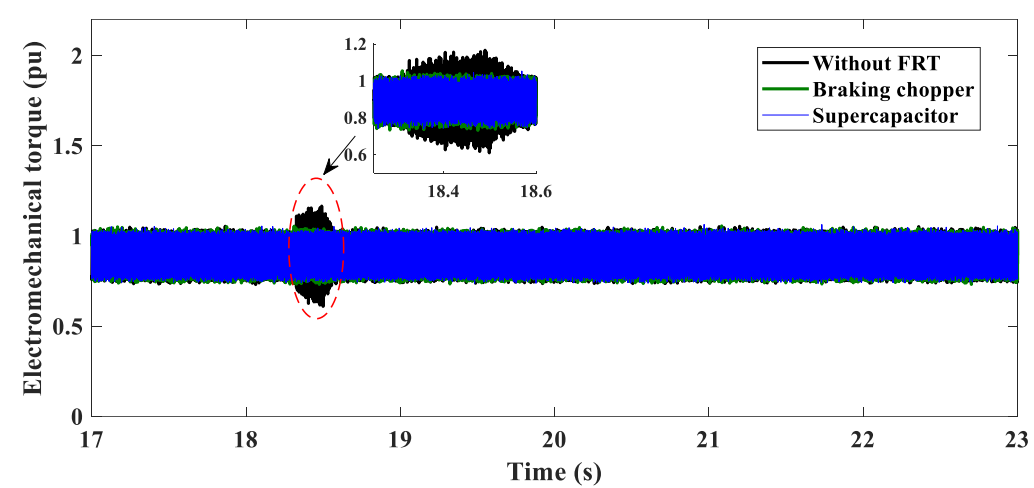

(d)

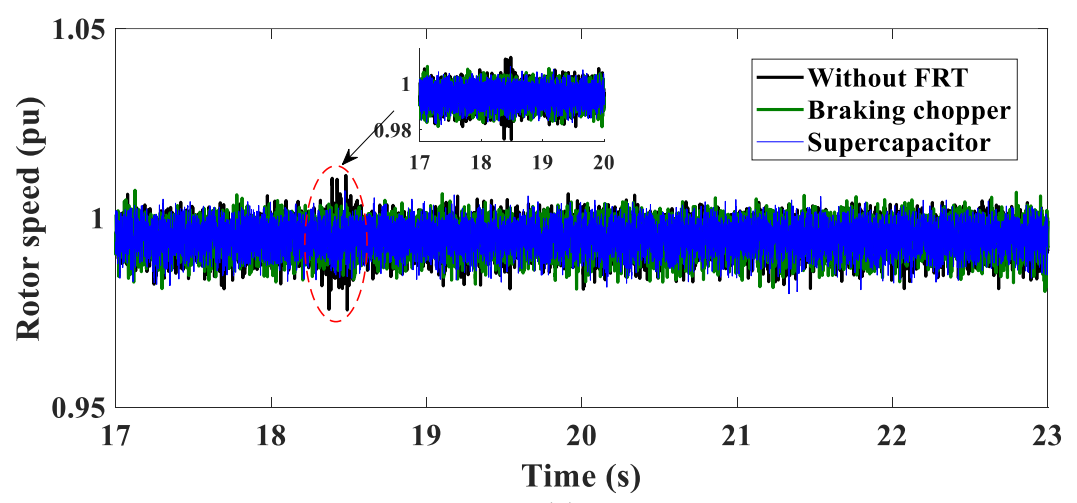

(e)

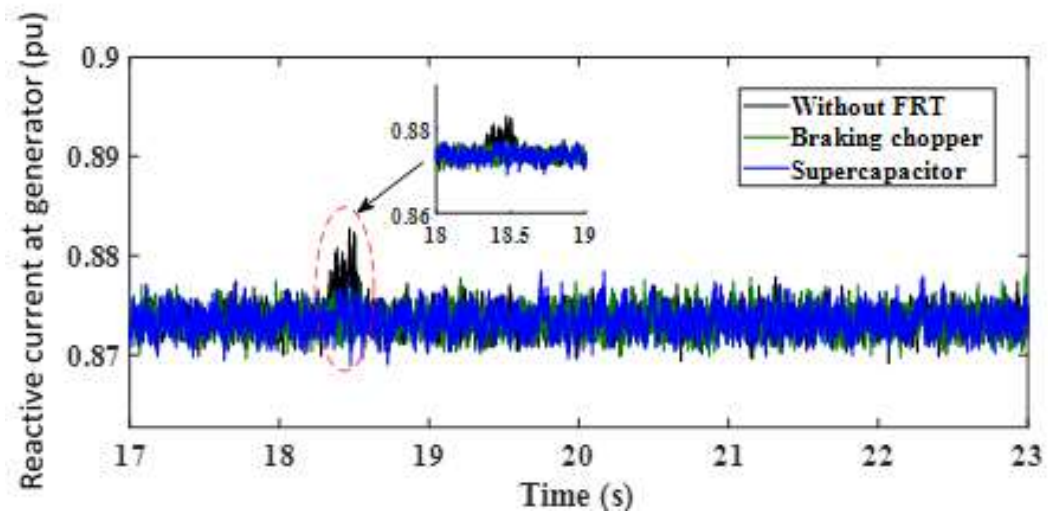

(f)

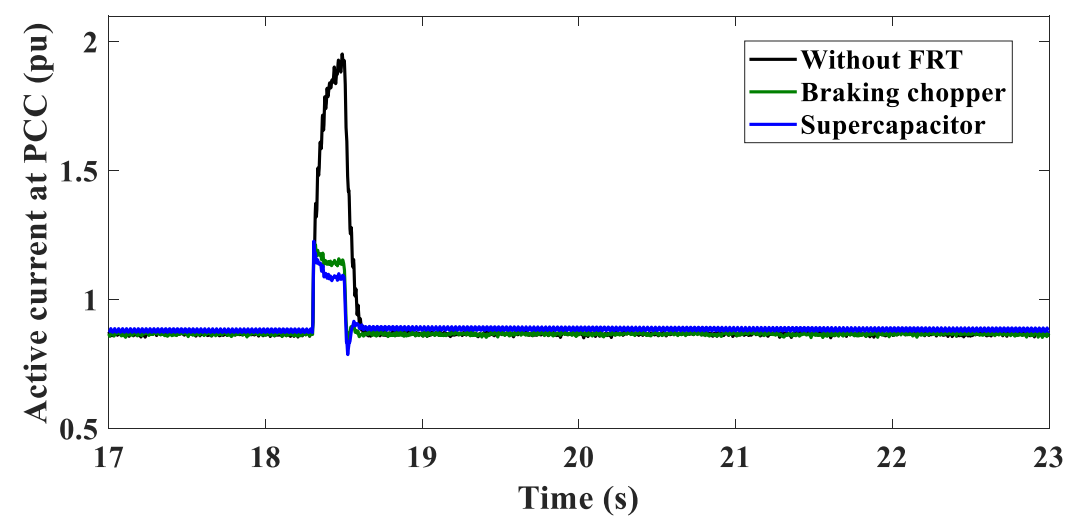

(g)

Figure 9. Dynamic response of PMSG under L-L to ground asymmetrical fault with BC and SC schemes: a) voltage at PCC; b) current at PCC; c) voltage of the DC link; d) electromechanical torque; e) rotor speed; f) reactive current at generator; g) active current at PCC. 


\section{Effect the BC and SCESS with Increasing Short Circuit Period}

The short circuit time is a significant parameter that strongly affects the system stability. Protection devices normally remove the fault within less than $300 \mathrm{~ms}$. In the following section, the fault duration increases from $150 \mathrm{~ms}$ to $250 \mathrm{~ms}$, where the implemented fault occurs at $t=18.3 \mathrm{~s}$ and resolved at $\mathrm{t}=18.55 \mathrm{~s}$. Figure 10 (a) shows the terminal voltage under a $3-\Phi$ fault that is applied between $18.3 \mathrm{~s}$ and $18.55 \mathrm{~s}$, with and without schemes. Figure 10 (b) presents the RMS currents during the fault with and without BC and SCESS, where the currents decrease because of connecting the BC into the system. The SCESS can continue in limiting currents and keeping the generator connected with the grid, even with the increase of the short circuit period.

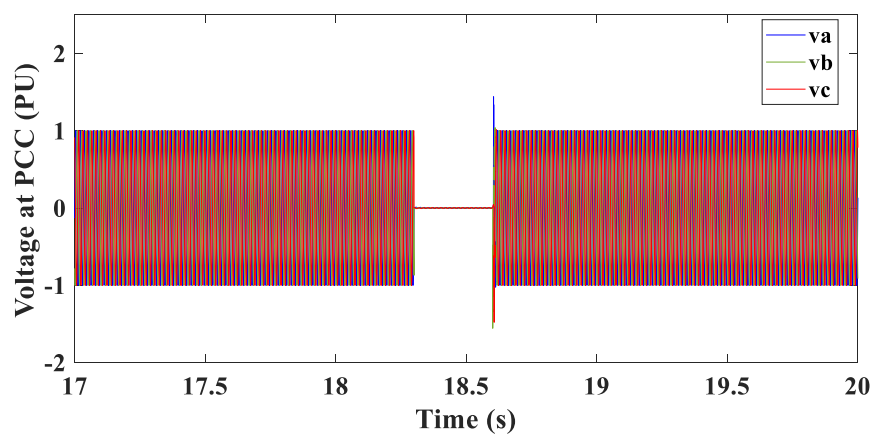

(a)

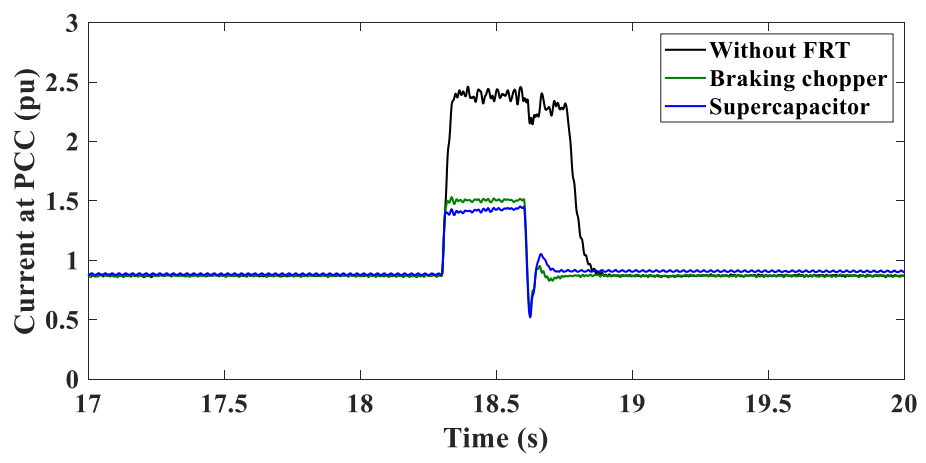

(b)

Figure 10. Dynamic response of PMSG under increasing short circuit period with BC and SC schemes: a) voltage at PCC; b) current at PCC.

\section{The Performance of PMSG Wind Turbine with a BC having Different Resistance values}

Dynamic simulations are performed to evaluate power quality, transient stability and LVRT capability of PM synchronous generator-wind energy system with unusual conditions assuming that a fault occurred at $5.3 \mathrm{~s}$ and cleared at $5.5 \mathrm{~s}$ as shown in Figure 11 (a). Surplus active power from the PM synchronous generator can be dissipated in the form of thermal energy by using a braking chopper, this prevents the DC link's voltage from increasing extensively. Figure 11 (b) presents the DC link voltage with different resistance values $(0.1,10$, and $30 \mathrm{ohms})$, where $\mathrm{R}=0.1 \Omega$ provides better performs for the $\mathrm{DC}$ link. Finally, it is clear that the active power, the speed of rotation and voltage of the DC-link 
are impacted considerably by the value of $\mathrm{BC}$ resistance. So, the $\mathrm{BC}$ resistance value must be accurately selected.

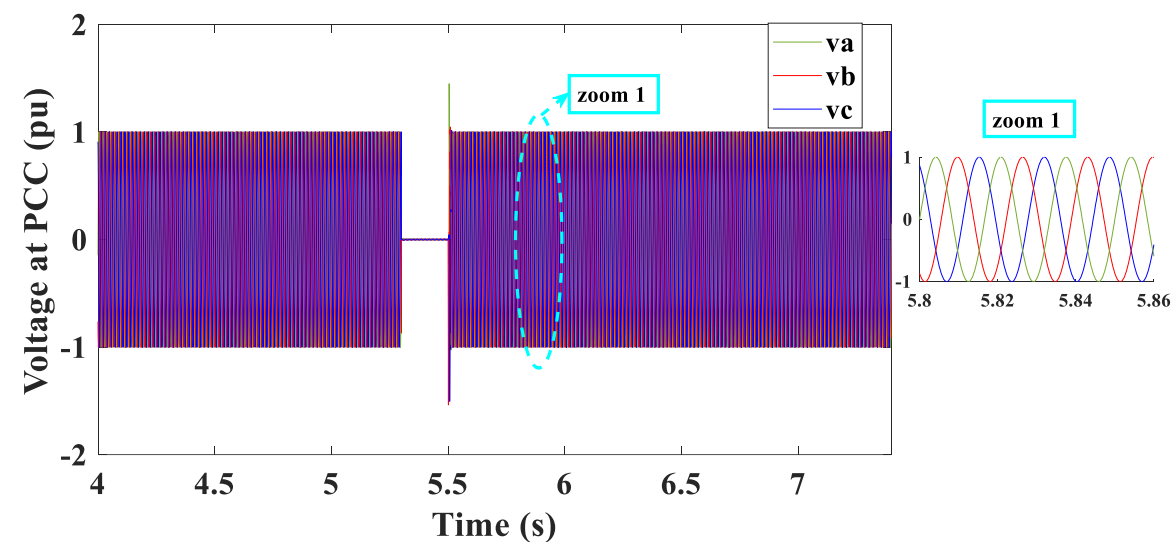

(a)

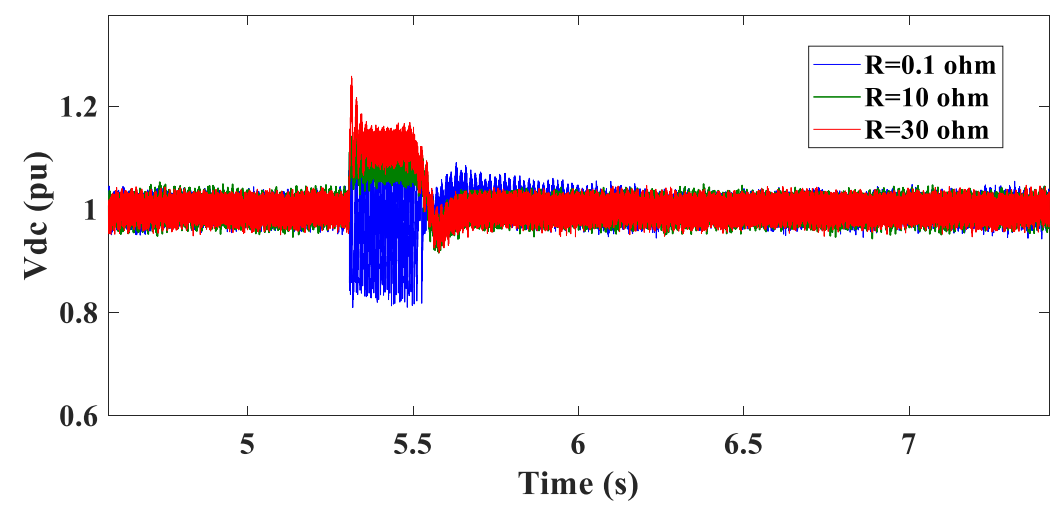

(b)

Figure 11. Dynamic response of PMSG with a BC having different resistance values: a) voltage at PCC; b) voltage of the DC link.

\section{Conclusions}

This paper demonstrated the enhancement of FRT capability of PM synchronous generator based on WECS with BC circuit and SCESS during various fault conditions, which is a significant affair for the wind turbine systems. The performance of PM synchronous generator-based wind energy is intensively investigated with asymmetrical and symmetrical faults, increasing short circuit period and varying the $\mathrm{BC}$ resistance values. The BC system is implemented to enhance FRT capability, but the improvement achieved by the SCESS method is noteworthy than BC method. The features of using SCESS are extended to the transient performance of PMSG after fault clearance, where PMSG returns faster to its normal state. In general, SCESS methodology provides superior performance and better FRT capability than the use of BC method.

\section{REFERENCES}

[1] M. Otmane, " MPPT control design for variable speed wind turbine r," International Journal of Electrical and Computer Engineering, vol. 10, no. 5, pp. 4604 4614.

[2] Q. Vi Ngo, " The maximum power point tracking based- control system for smallscale wind turbine using fuzzy logic," International Journal of Electrical and Computer Engineering, vol. 10, no. 4, pp. 3927 3935, Jun. 2020. 
[3] M.; Cardenas, R.; Molinas, "Overview of Multi-MW Wind Turbines and Wind Parks," IEEE Trans. Ind. Electron, vol. 58, no. 4, 2011.

[4] H. Chen, "Overview of different wind generator systems and their comparisons," IET Renew Power Gener, vol. 2, no. 2, 2008.

[5] F. Blaabjerg, F. Hansen, "Review of contemporary wind turbine concepts and their market penetration," Wind Eng. Ind. Aerodyn, vol. 28, no. 3, 2004.

[6] R. Pena, R. Alepuz, "Overview of Control Systems for the Operation of DFIGs in Wind Energy Applications," IEEE Trans. Ind. Electron, vol. 60, no. 7, 2013.

[7] A. H. K. Alaboudy, A. M. Azmy, and W.S.E. Abdellatif, "Controller performance of 322 variable speed wind driven doubly-fed induction generator," IEEE Saudi Arabia Smart Grid 323 (SASG) Conference, 7-9 Dec. 2015.

[8] W.S.E. Abdellatif, A. H. K. Alaboudy, and A. M. Azmy," Comparison between Outer Crowbar and RSFCL for LVRT Capability Enhancement of Wind Turbines Conversion System," 2019 Twentieth International Middle East Power Systems Conference (MEPCON), Tanta University, Egypt, 2019.

[9] M. Arnaltes, S. Burgos, "Control of permanent magnet generators applied to variablespeed wind-energy systems connected to the grid," IEEE Trans. Energy Convers, vol. 21, no. 1, pp. 130-135, March 2006.

[10] M. Hackl, C. Zhang, "Sensorless Control of Permanent Magnet Synchronous Generators in Variable-Speed Wind Turbine Systems.," Power and Energy Student Summit (PESS 2016), Aachen, Germany, 19-20 January 2016.

[11] J. F. Conroy and R. Watson, "Low-voltage ride-through of a full converter wind turbine with permanent magnet generator," IET Renew. Power Gener., $\quad$ vol. 1, no. 3, pp. 182-189, Sep. 2007.

[12] J. Watson, "Low-voltage ride-through of a full converter wind turbine with permanent magnet generator," IET Renew. Power Gener, vol. 1, no. 3, 2007.

[13] V.F. Matos, S.Y.; Cupertino, "Low Voltage Ride-Through Capability Solutions for Permanent Magnet Synchronous Wind Generators," Energies, vol. 9, no. 1, 2016.

[14] N. Jiao, L. Peng, "Improved control strategy of an active crowbar for directly-driven PM wind generation system under grid voltage dips," International Conference on Electrical Machines and Systems (ICEMS), Wuhan, China, 17-20 October 2008. [15] Y. Li, Z. Wen, "Power Quality Improvement and LVRT Capability Enhancement of Wind Farms by Means of an Inductive Filtering Method," Energies, vol. 9, no. 4, 2016. [16] S.W. Aware, "STATCOM-control scheme for grid connected wind energy system for power quality improvement," IEEE Syst, , vol. 20, no. 1, 2010.

[17] L. Truong, "Dynamic stability improvement of four parallel-operated PMSG-based offshore wind turbine generators fed to a power system using a STATCOM," IEEE Trans. Power Deliv, vol. 28, no. 1, 2013.

[18] T. Lee, "Ride-through technique for PMSG wind turbines using energy storage systems," J. Power Electron, vol. 10, no. 6, 2010.

[19] B. Bernhoff, H. Leijon, "Flywheel energy and power storage systems," Renew. Sustain. Energy Rev, vol. 11 no. 2, 2007.

[20] L. Morrow, "Wind turbines with energy storage for power smoothing and FRT enhancement," IEEE Power and Energy Society General Meeting, San Diego, CA, USA, 24-29 July 2011.

[21] A.D. Michalke, "Modelling and control of variable-speed multi-pole permanent magnet synchronous generator wind turbine," Wind Energy 2008, vol. 11, no. 5, 2008. 
[22] Jiao L, Peng Z, "Improved control strategy of an active crowbar for directly-driven PM wind generation system under grid voltage dips," International Conference on Electrical Machines and Systems (ICEMS); 2008.

[23] A. Schneuwly, "Charge ahead ultracapacitor technology and applications," IET Power Eng. J. 19, 34-37, vol. 19, no. 1, Feb.-March 2005.

[24] M. Abido, "Supercapacitors for wind power application," In: $2^{\text {nd }}$ International Conference on Renewable Energy Research and Applications, 20-23 Oct, Madrid, Spain 2013.

[25] Y. Cheng, "Assessments of energy capacity and energy losses of supercapacitors in fast charging-discharging cycles," IEEE Trans. Energy Convers. vol. 25, no. 1, 2010.

[26] Y.W. Muhammed, "Power smoothing control of PMSG based wind generation using supercapacitor energy storage system," Int. J. Emerg. Electr. Power Syst. https://doi.org/10.1515/ijeeps-2016-0181 2017.

[27] A. Abedini, "Applications of Super Capacitors for PMSG Wind Turbine Power Smoothing," Conference of IEEE Industrial Electronics, Nov. 2008.

[28] Y. Worku, "Fault Ride-Through and Power Smoothing Control of PMSG-Based Wind Generation Using Super Capacitor Energy Storage System," Arabian Journal for Science and Engineering, April 2018.

[29] M. M. Chowdhury, "A Direct Drive Grid Connected Wind Energy System with STATCOM and Super-capacitor Energy Storage," 2012 IEEE International Conference on Power System Technology (POWERCON), 2 Nov. 2012.

[30] TH. Nauyen, "Ride-through technique for PMSG wind turbines using energy storage systems," Journal of Power Electron, vol. 10, no. 6, 2010.

[31] TH. Nguyen, "Advanced fault ride-through technique for PMSG wind turbine systems using line-side converter as STATCOM," IEEE Trans Ind Electron, vol. 60, no. 7, 2013.

[32] W.S.E. Abdellatif, A. H. K. Alaboudy, and A. M. Azmy," Fault-ride through capability enhancement of DFIG-based wind turbines by SFCL," 2018 Twentieth International Middle East Power Systems Conference (MEPCON), Cairo University, Egypt, 2018..

[33] T. Pan, Z. Ji, Z. Jiang, "Maximum power point tracking of wind energy conversion systems based on sliding mode extremum seeking control," Proceedings of IEEE Energy 2030, Atlanta, USA, pp. 1-5. GA, 17-18 November 2008.

[34] G. P. Adam, K. H. Ahmed, S. J. Finney, K. Bell, and B. W. Williams, "New breed of network fault-tolerant voltage-source-converter HVDC transmission system," IEEE Trans. on Power Systems, vol. 28, no. 1, pp. 0885-8950, Feb. 2013.

[35] D. Zammit, C. Spiteri, "Incremental current based MPPT for a PMSG micro wind turbine in a grid-connected DC micro grid," $9^{\text {th }}$ International Conference on Applied Energy, P 2284-2294, 2017.

[36] M. Chinchilia, S. Arnaltes, and J. Burgos, "Control of permanent-magnet generator applied to variable-speed wind-energy systems connected to the grid, " IEEE Trans. Energy Conversion, vol. 21, no.1, Mar. 2006.

[37] S. Li, T. A. Haskew, and L. Xu, "Conventional and novel control designs for direct driven PMSG wind turbines," Electric Power System Research, vol. 80, no. 3, pp. 328-338, Oct. 2009.

[38] S. M. Muyeen, R. Takahashi, T. Murata, and J. Tamura, "A Variable speed wind turbine control strategy to meet wind farm grid code requirements," IEEE Trans. Power Systems, vol. 25, no.1, Feb. 2010. 
[39] A. H. Kasem, E. F. El-Saadany, H. H. El-Tamaly, and M. A. A. Wahab, "An improved fault ride-through strategy for doubly fed induction generator-based wind turbines," IET Renewable Power Generation, vol. 2, no. 4, pp. 201-214, Dec. 2008.

[40] Y. Lang, N. Zargari, and S. Kouro, "Power conversion and control of wind energy systems," John Wiley \& Sons, Inc., Hoboken, New Jersey, 2011.

[41] Z. Qiu, K. Zhou, and Y. Li, "Modeling and control of diode rectifier fed PMSG based wind turbine," in Electric Utility Deregulation and Restructuring and Power Technologies (DRPT), $20114^{\text {th }}$ International Conference on, pp. 1384-1388, 2011.

[42] P. Sumner, L. Parashar, "Power system stabilisation using STATCOM with supercapacitors," In: ISA’08 IEEE Industry Applications Society Annual Meeting, 2008. 